\title{
Chemoprevention of HBV-related hepatocellular carcinoma by the combined product of resveratrol and silymarin in transgenic mice
}

\section{Wen-Chuan Hsieh ${ }^{1}$, Ching-Wen Yang ${ }^{2}$, Yi-Sheng Haung ${ }^{1}$, Ting-Wei Chao ${ }^{1}$, Tin-Fen $\mathrm{Tsai}^{3}$ and Ih-Jen $\mathrm{Su}^{1,2}$}

\author{
1*National Institute of Infectious Diseases and Vaccinology, National Health Research \\ Institutes, Tainan, Taiwan; ${ }^{2 *}$ Institute of Basic Medical Research, National Cheng Kung \\ University Medical School, Tainan, Taiwan; ${ }^{3}$ Faculty of Life Sciences and Institute of \\ Genetics, National Yang-Ming University, Taipei, Taiwan.
}

Corresponding author: Prof. Ih-Jen Su, National Institute of Infectious Disease and Vaccinology, National Health Research Institutes, Tainan, Taiwan

Submission date: April 11, 2013; Acceptance date: September 24, 2013; Publication date: September 30, 2013

\begin{abstract}
Background: Patients with chronic hepatitis B virus (HBV) infection are at a high risk to develop hepatocellular carcinoma (HCC). Recently, metabolic syndrome has been found to carry a risk for HCC development. Considering the limitation of chemotherapeutic drugs for HCCs, the development of chemopreventive agents for high risk chronic HBV carriers is urgently demanded. In this study, we used combined silymarin and resveratrol extract which have been shown to exhibit biologic effects on activating peroxisome proliferator activated receptors (PPAR) and inhibiting mTOR signaling in a transgenic mice model harboring HBV viral oncoproteins.
\end{abstract}

Methods: The transgenic mice model harboring HBx and pre-S2 mutant constructs which develop HCC was adopted. First, we in vitro tested the ideal combination dosages of the silymarin and resveratrol product, and then we fed the natural product to the transgenic mice. The chemopreventive effects on preventing the development of HCC were evaluated.

Results: MTT assay showed an enhanced effect of the combined silymarin and resveratrol product on the reduction of cell proliferation in two hepatoma cell lines, Huh-7 and Hep G2. In vitro reporter assay and Western blot analyses revealed that the combined product could activate PPAR/PGC-1 $\alpha$ signaling and inhibit mTOR expression. In vivo, the combined products could significantly ameliorate fatty liver and reduce HCCs in transgenic mice harboring HBV oncoproteins.

Conclusions: The combined silymarin and resveratrol product exhibits a synergistic effect on the reduction of HCC development in transgenic mice model and may represent a potential agent for the prevention of HCC in high risk chronic HBV carriers. 
Key words: HBV, HCC, Transgenic mice, Chemoprevention

\section{INTRODUCTION:}

Hepatocellular carcinoma (HCC) is one of the most common types of cancer worldwide and is the second most frequent cause of cancer death in men [1]. The major risk factors for HCC include chronic infection with hepatitis $\mathrm{C}$ virus (HCV) or hepatitis $\mathrm{B}$ virus (HBV), and excessive alcohol consumption [2]. Chronic hepatitis B virus (HBV) infection and HBV-related hepatocellular carcinoma (HCC) remain one of the major health problems in Taiwan, mainland China, and other parts of the world [3]. Among the mechanisms of HBV hepatocarcinogenesis, $\mathrm{HBx}$ has been recognized as a viral oncoprotein and many HBV-related signal pathways have been reported to be potential oncopathways, including the recently reported mTOR (mamalian target of rapamycin) signaling [4-6]. Besides HBx, we proposed that the emergence of a second HBV oncoprotein, the pre-S2 deletion mutant in Type II ground glass hepatocytes (GGH) at the advanced stage of chronic HBV infection [7, 8]. The pre-S2 deletion mutant can induce endoplasmic reticulum (ER) stress and initiate ER stress-dependent and -independent signals, leading to NF- $\square \mathrm{B}$ activation, COX-2 induction, oxidative DNA damage, and genomic instability [9-11]. The pre-S2 deletion mutants can also activate the VEGF-A and mTOR signal pathway $[12,13]$. Therefore, GGHs are now recognized as a pre-neoplastic lesion of $\mathrm{HCC}$ and pre-S2 deletion mutant as a new viral oncoprotein.

Although anti-viral drugs have been shown effective in controlling the HBV infection, the progression from chronic $\mathrm{HBV}$ infection to $\mathrm{HCC}$ still remains a nightmare for the majority of chronic HBV carriers. Target drugs have been developed for therapeutic trial of HCC, but the efficacy is still limited. Furthermore, no chemopreventive agents or natural products have been tried to prevent or revert the disease progression from chronic HBV infection to HCC. The reasons for this difficulty to apply chemoprevention for HBV-related $\mathrm{HCC}$ is due to the lack of knowledge for the molecular mechanism of HBV tumorigenesis or the disease progression from their precursor lesions to HCC, and also the lack of suitable chemopreventive products. Recently, patients with metabolic syndrome have been found to carry a high risk to develop HCC $[14,15]$. For chemoprevention of cancer development or recurrence, natural products with active ingredients and without side effects are most ideal considering the long-term usage.

Besides HBV or HCV infection, nonalcoholic fatty liver disease, inflammation, and metabolic syndrome have been recognized to be the risk factors for HCC development. Furthermore, small-sized HCC, either HBV- or HCV-related, frequently showed fatty change, suggesting that lipid metabolism is disturbed at the advanced stage of chronic liver disease and HCC $[16,17]$. Recently, mTOR signaling has been found to play a regulator role in the metabolic syndrome and HBV tumorigenesis [18-20]. It can regulate the lipid biosythesis through the SREBP-1 to activate peroxisome proliferator activated receptors (PPAR)- $\gamma$ and lipid-related genes which may contribute to tumorigenesis [18, 21, 22]. 
Among the natural products, silymarin is the ideal candidate product for chemoprevention of HCCs because of their popular and long-term usage for chronic liver diseases in human community (23). Silymarin, a compound from milk thistle (Silybum marianum), has been widely consumed as a dietary supplement and an empirical product widely used for liver diseases. The active component-silibinin has been evaluated clinically in the treatment of hepatitis and liver damage because of its anti-inflammation and anti-oxidant effects $[23,24]$. Recent evidence also suggests that silymarin and silibinin may be useful in the chemoprevention of malignancies in a variety of sites including liver cancer $[25,26]$. The other ideal candidate for HCC chemoprevention is the resveratrol from grape skin extract which has been verified to be effective to prevent cancer development at various stages of carcinogenesis including initiation, promotion, tumor invasion, and metastatsis [25, 27-29]. Resveratrol is a strong anti-oxidant and anti- inflammatory agent [30, 31], and also a most promising product for metabolic syndrome and longevity through mTOR inhibition and upregulation of PPARs and PGC-1 $\alpha$ [31-33]. Therefore, the combination of silymarin and resveratrol will be a potential candidate for chemoprevention of HCCs in high risk chronic HBV carriers.

In this study, the in vitro and in vivo effects of silymarin and resveratrol, either alone or in combination, were evaluated in inhibiting the proliferation of HCC cell lines by MTT assay. Their activities in regulating PPARs, PGC-1 and mTOR activities were tested by the reporter assay or Western blot analyses. The ideal combination of these two products were then fed to the transgenic mice harboring the double HBV oncoproteins (HBX and pre-S2 mutants) for chemoprevention of HCC development.

\section{METHODS:}

\section{Cell proliferation assay}

A total $5 \times 10^{3}$ cells/well was seeded in the 96 well plate. After treatment of silymarin (Sigma, St. Louis, MO), resveratrol (Calbiochem, Darmstadt, Germany), or both for 24 hour and 48 hour, Cell Counting Kit-8 solution (Sigma, St. Louis, MO)) was added to each well and then incubated the plate for three hours at $37^{\circ} \mathrm{C}$ Then the plate was measured the absorbance at $450 \mathrm{~nm}$.

\section{Luciferase reporter assay}

PPAR- $\gamma$-LBD and pRL-TK plasmids were used in PPAR- $\gamma$ activity analysis. After transfection with lipofectamine 2000 (Invitrogen, Carlsbad, CA92008), luciferase-expressed cells were assayed by the Dual-Luciferase Reporter Assay System (Promega, Madison, W1, USA), according to the manufacturer's instructions. Renilla luciferase activities were measured for normalization.

\section{Western blot analyses}

Cells were harvested after treated with silymarin, resveratrol, or both for 48 hours and then lysed in RIPA buffer (Upstate Biotechnology, NY) containing proteinase inhibitor cocktail and phosphatase inhibitor (Roche Applied Science, Indianapolis, IN). Total protein lysate was then harvested via centrifugation at 13,000 rpm for 20 minutes, resolved on SDS-PAGE and transferred to PVDF membranes. After incubated with primary antibodies and following 
secondary antibodies, the membranes were visualized by ECL (PerkinElmer Life Science, Boston, MA). Antibodies used in this study were anti-PPAR- $\gamma$ (Abcam, MA, USA), anti-PGC1 $\square$ (Abcam, Cambridge, UK), anti-SIRT1 (Abcam, Cambridge, UK), anti-p-mTOR (Abcam, Cambridge, UK) and anti- $\beta$-actin (Chemicon, Temecula, CA).

\section{Transgenic animal model harboring double $\mathrm{HBx}$ and pre-S2 mutant constructs}

Transgenic mice harboring HBx and pre-S2 mutant were established using the liver-specific transgenic vector pAlb-In-pA-HS4 as described previously [26]. The albumin-HBx or pre-S2 mutant (nt 4-57 deletion) [9] transgenic mice were generated by pronucleus microinjection of C57BL/6 fertilized eggs. The transgenic mice harboring both $\mathrm{HBx}$ and pre-S2 mutants were obtained by hybridizing the HBx-transgenic mice and pre-S2 mutant-transgenic mice. The HBx and pre-S2 mutant transgenic mice are bred and screened for the HCC chemoprevention study. All of the mice used in this study were male and housed in a specific pathogen free facility. All the animal experiments have been performed under the approval of the Institutional Animal Care and Use Committees of the National Cheng Kung University Medical School and National Health Research Institutes.

\section{Preparation of natural products for chemoprevention}

The natural product-silymarin was purchased from Indena (Indena, Milan, Italy). This product is an extract from Milk Thistle and contained 35\% silybin in a phytosome complex as assayed by HPLC. The natural product-Vineatrol ${ }^{\circledR}$ 20-6 was purchased from Breko (Breko $\mathrm{GmbH}$, Bremen, German). This product is an extract from grape vine and contained resveratrol of $20 \%$ as revealed by HPLC assay. Silymarin (0.875 mg Silymarin/g chow), resveratrol $\left(0.875 \mathrm{mg}\right.$ Vineatrol ${ }^{\circledR} / \mathrm{g}$ chow $)$, or both were added and mixed with normal chow diet.

\section{Animal study for HCC chemoprevention}

Four groups of transgenic mice were fed with normal chow diets or chow diets containing silymarin, resveratrol or both at the age of 8 months for six months (at the age of 14 months) and then sacrificed for evaluation. The residual chow diets were weighed weekly for controlling amount of mice uptake. These mice were weighed each week and measured ALT monthly. The tumor development (including tumor size and tumor number) in each group was evaluated and analyzed by biostatistics.

\section{Histopathology}

Mice were sacrificed after being fed natural products for 6 months. Liver tissues were then collected, fixed with $10 \%$ neutral formalin, and embedded in paraffin. These paraffin-embedded liver tissues were sectioned at $4 \mu \mathrm{m}$ thickness and further subjected to hematoxylin-eosin (H\&E) staining for conventional histopathological observation. Fat accumulation in liver was examined by Oil-Red $\mathrm{O}$ staining of cryostat frozen sections as described previously [34].

\section{Statistical analysis}

Statistical analyses were carried out using GraphPad Prism 4. Data was analyzed by 
Kruskal-Wallis test and Dunn's post test. $P$ value $<0.05$ was considered significant.

\section{RESULTS and DISCUSSIONS:}

\section{In Vitro Study: enhanced activity of combined silymarin and resveratrol product on the inhibition of tumor cell proliferation}

We first tested the effect of silymarin and resveratrol on two hepatoma cell lines, Huh-7 and Hep-G2. Different doses of silymarin $(0,25,50,100$ and $200 \mu \mathrm{g} / \mathrm{ml})$ and resveratrol $(0,10$, 20 , and $40 \mu \mathrm{g} / \mathrm{ml}$ ) were studied by MTT assay on both cell lines. The results showed a reduction of cell proliferation on both Huh 7 and Hep G 2 cell lines. The best combination dosage for the anti-proliferation effect on both cell lines were determined at around the ratio of 1:2.5-1:5 for resveratrol and silymarin, respectively in combination (Figure 1).
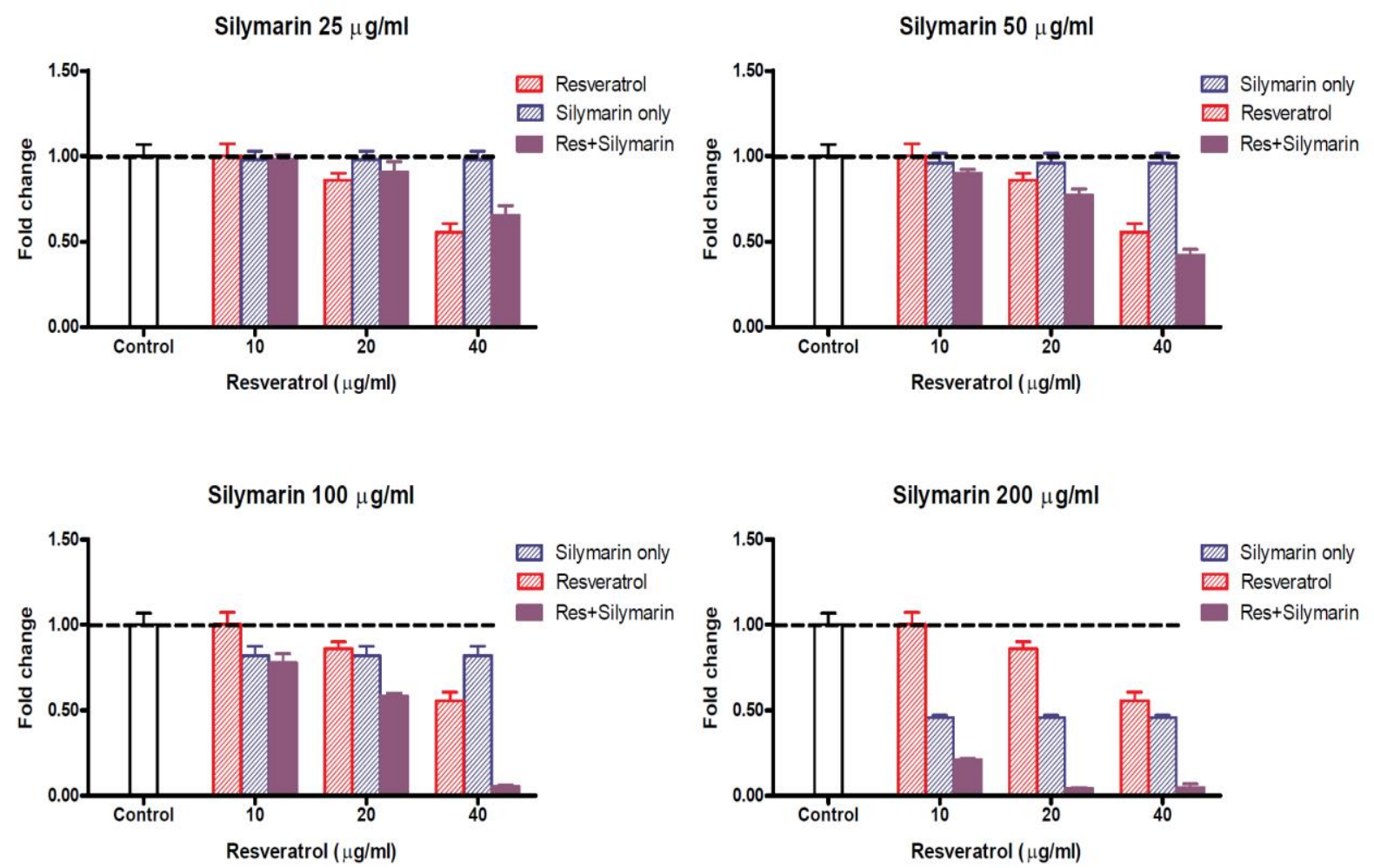

Figure 1. Anti-proliferation effect of resveratrol combined with silymarin on Huh-7 hepatoma cell line

We then determined the effects of the combined product on the regulation of PPAR $\gamma$, PGC-1 $\alpha$, and p-mTOR. Resveratrol has been reported that can activate PGC- $1 \alpha$ which acts as a co-activator of PPAR- $\gamma$. We chose $100 \mu \mathrm{g} / \mathrm{ml}$ silymarin combined with 40 or $80 \mu \mathrm{M}$ resveratrol based on the above-described MTT results to test their effects on the regulation of PPAR- $\gamma$, PGC- $1 \alpha$ and p-mTOR. The PPAR- $\gamma$ activities were determined by the luciferase reporter assay, while Western blot analyses were used to evaluate the expression of PGC-1 $\alpha$ and p-mTOR. Our results showed that resveratrol combined with silymarin had synergistic effects on increasing the PPAR- $\gamma$ activities in both Huh-7 and Hep-G2 cell lines (Figure 2A). 
Western blot analyses showed that the combined silymarin $(100 \mu \mathrm{g} / \mathrm{ml})$ and resveratrol (80 $\mu \mathrm{M})$ exhibited the significant enhanced activities to inhibit mTOR and increased PGC-1 $\alpha$ ( Figure 2B ).

(A)

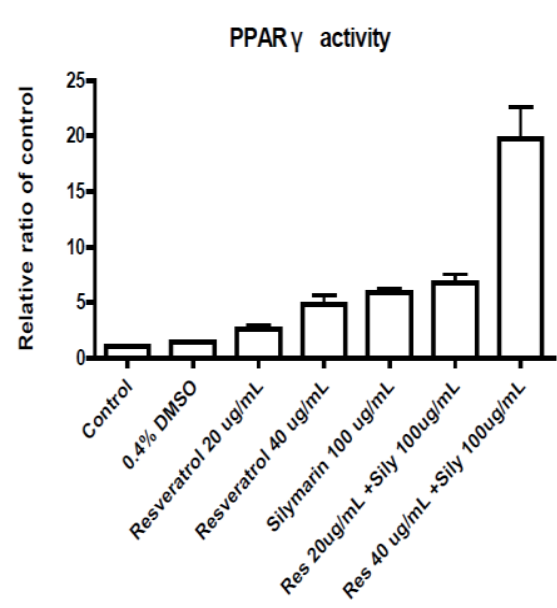

(B)

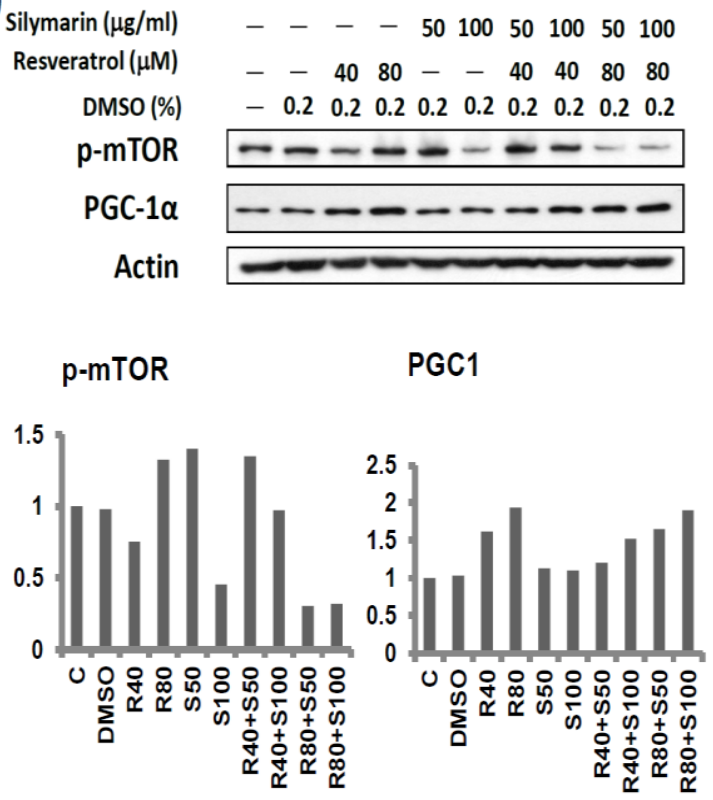

Figure 2. Synergistic effect of resveratrol combined with silymarin on PPAR- $\gamma$ activity, p-mTOR inhibition, and enhanced PGC-1 $\alpha$

Considering the absorbability and catabolism in vivo, we then performed a pilot in vivo study for testing the effects of the different dosages of the combined product on mice.

\section{In Vivo dosage test}

In this study, we used 4-week-old of HBx transgenic male mice (C57BL/6 background) for testing the effect of combined product on the early stage of liver pathogenesis. The HBx transgenic male mice and their wild type male littermates were randomly assigned into different groups. Resveratrol (20 mg/kg) combined with various doses of silymarin $(15,30$, and $60 \mathrm{mg} / \mathrm{kg}$ ) were fed to mice daily through p.o administration using feeding needles for two weeks (14 days) and then mice were sacrificed for analysis. From H\&E and oil-red staining, the liver of $\mathrm{HBx}$-transgenic mice without any treatment showed minor fatty change at the age of 6 weeks, but it improved after treatment of resveratrol $(20 \mathrm{mg} / \mathrm{kg})$ combined with Silymarin $(15 \mathrm{mg} / \mathrm{kg}, 30 \mathrm{mg} / \mathrm{kg}$ and $60 \mathrm{mg} / \mathrm{kg}$ ). The $\mathrm{HBx}$ transgenic livers recovered to almost normal morphology in the group of $20 \mathrm{mg} / \mathrm{kg}$ resveratrol combined either $30 \mathrm{mg} / \mathrm{kg}$ silymarin or $60 \mathrm{mg} / \mathrm{kg}$ silymarin group. In the group of $20 \mathrm{~kg} / \mathrm{ml}$ resveratrol combined with silymarin $30 \mathrm{mg} / \mathrm{kg}$, it showed significant improvement of fatty change as compared to the group of either resveratrol or silymarin alone (Figure 3A and 3B). 
(A) HE staining

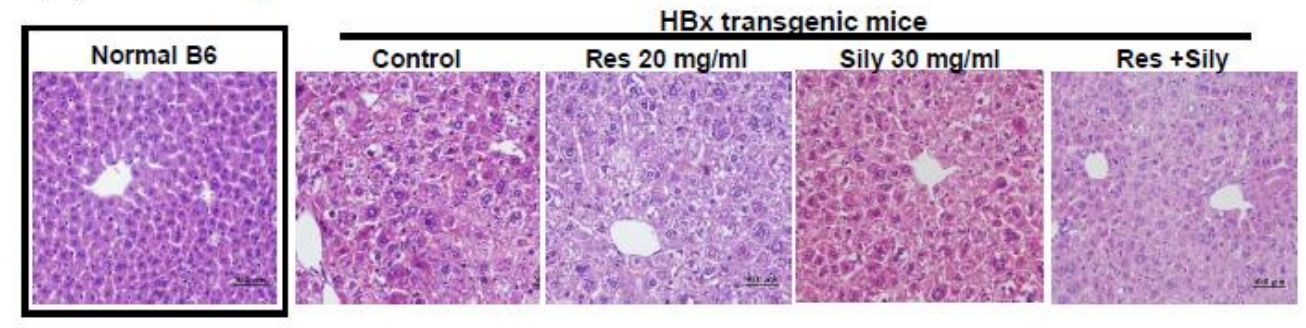

(B) Oil-red staining

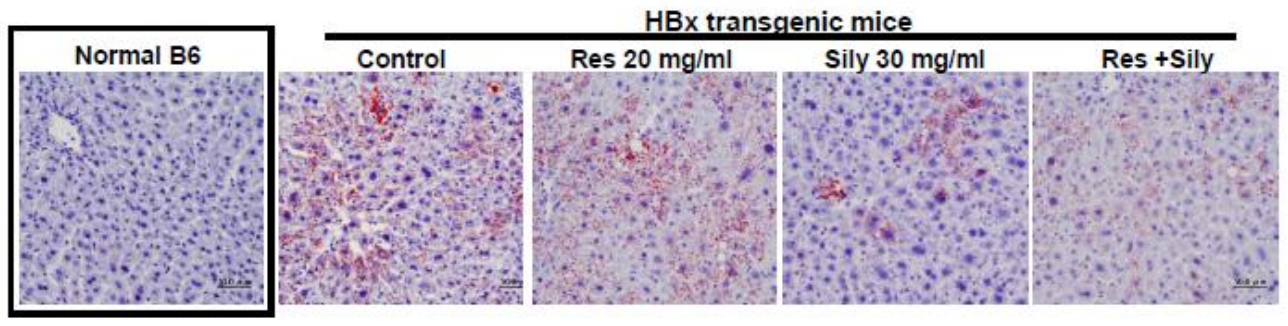

Figure 3. Beneficial effects of resveratrol combined with silymarin on liver damage and fatty changes.

\section{Toxicity studies}

Serum ALT observed in both wild-type and HBx transgenic mice are in a normal range (20-50 U/L) at the age of 4-6 weeks. No obvious difference in the serum ALT was detected among control and treatment groups. Taken together the liver pathology and serum biochemistry, the findings indicate that resveratrol $(20 \mathrm{mg} / \mathrm{kg})$, silymarin $(15,30$ and 60 $\mathrm{mg} / \mathrm{kg}$ ) or the combined product showed no toxic effect on liver at this age of mice. Therefore, the combination of these two natural products $(20 \mathrm{~kg} / \mathrm{ml}$ resveratrol and $30 \mathrm{~kg} / \mathrm{ml}$ silymarin) will be a safe agent for chemopreventon on HBV-related HCC animal model.

Chemoprevention design based on the molecular mechanism of HBV tumorigenesis by using the combined products on transgenic mice harboring both HBx and pre-S2 mutant

Recently, we demonstrated that GGHs co-expressing both HBx and pre-S2 mutant exhibited an enhanced tumorigenesis pertinent to human $\mathrm{HBV} / \mathrm{HCC}$ development. A transgenic animal model harboring the double-construct $\mathrm{HBx}$ and pre-S2 mutant has been successfully established in our laboratory and was adopted in this study for chemoprevention study. The study design is based on the molecular mechanism of HBV tumorgenesis we previously proposed [34] (Figure 4). 
Proposed model of HBV-HCC progression:

PPAR- $\alpha / \gamma$ and AKT/mTOR are the candidate targets for chemoprevention in high risk $\mathrm{HBV}$ carriers

\section{Chemoprevention for \\ anti-inflammation \\ and lipid metabolism}

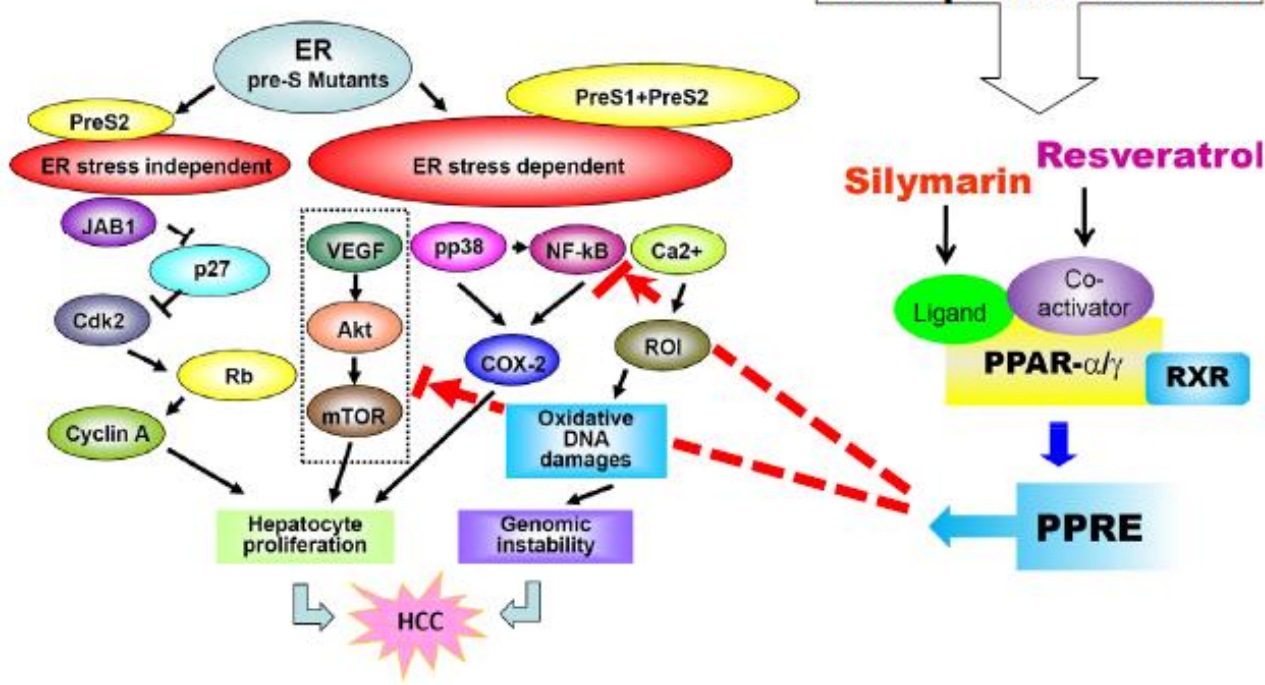

Figure 4. Design of chemoprevention based on the molecular mechanism of HBV tumorigenesis.

Tumor development was reduced in transgenic mice harboring double HBx plus pre-S2 mutants fed with combined silymarin and resveratrol product

The natural product for chemoprevention is prepared by combining extracts of silymarin and resveratrol, based on the concentration and dosages used in in vitro and in vivo dosage studies. The component of the extract for resveratrol is $20 \%$ purity, while that of silymarin is $35 \%$ purity based on the HPLC profile analyses provided by the manufacturers. These products were prepared as chow diets to feed the transgenic mice ( $4 \mathrm{~g}$ chow/mouse/day), including control group (normal chow diets), silymarin group, resveratrol group and combined silymarin plus resveratrol group. In the transgenic mice harboring double HBx and pre-S2 constructs, the results showed that tumor development was significantly reduced in the group fed with resveratrol or silymarin alone, or in the combined product group (Figure 5). However, the combined product showed remarkable for the tumors lager than $5 \mathrm{~mm}$ diameter, from $50 \%$ in the control group to $12.5 \%$ in the combined product group, as compared to that in the group of resveratrol $(45 \%)$ or silymarin $(47 \%)$ alone. The data indicate that the combined resveratrol and silymarin product exhibited a synergistic effect on reducing $\mathrm{HCC}$ development in this transgenic mice model which is pertinent to human HBV-related HCC. In this study, to ensure whether other ingredients in these extracts have additional effects, these chow diets (containing silymarin, resveratrol or both) were also fed to wild-type mice (for control and toxicity observation). Both ALT in serum and liver pathology showed no abnormal change after feeding these diets. 


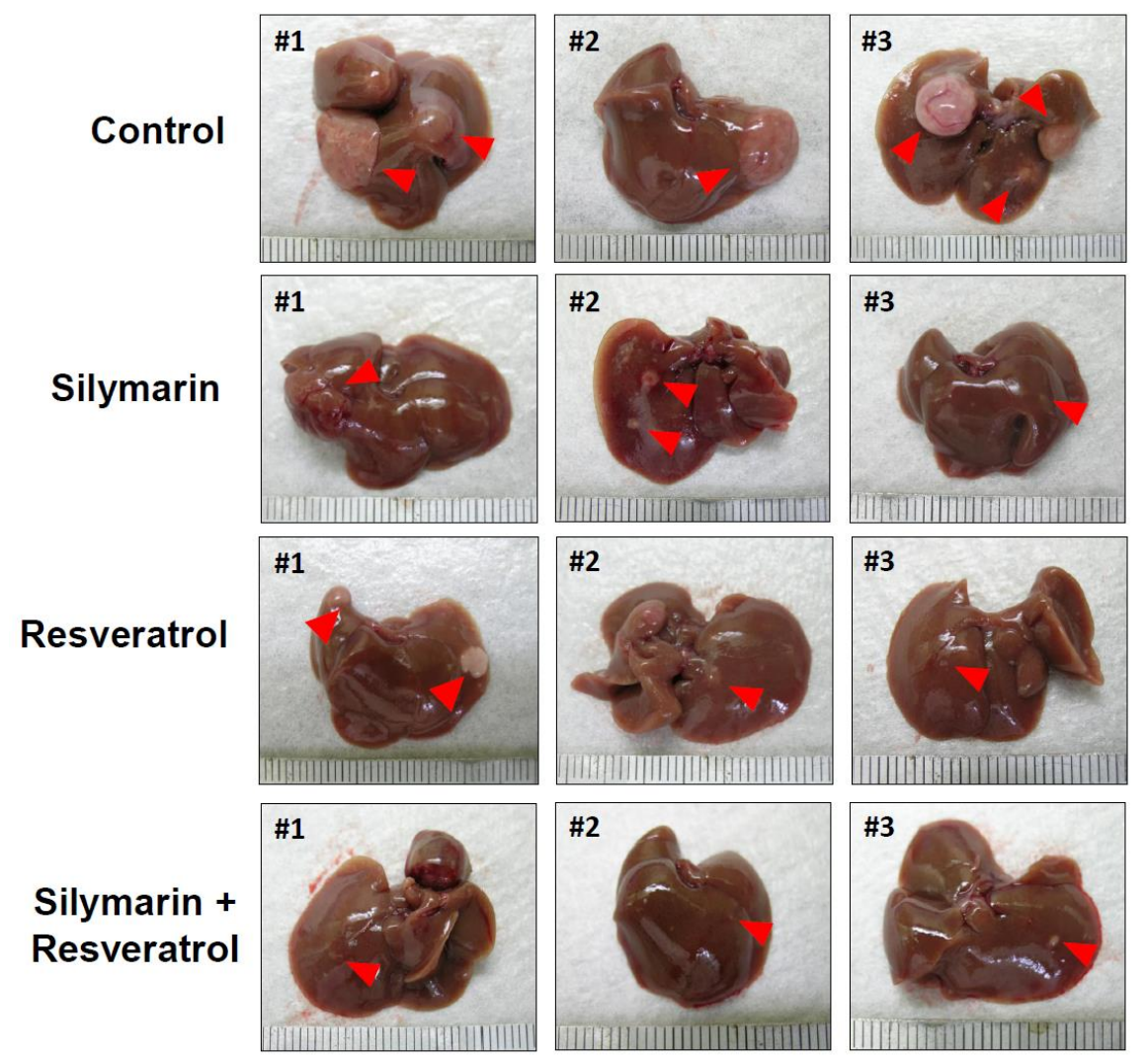

Figure 5. Tumor development in transgenic mice was significantly reduced in the group of feeding combined silymarin and resveratrol product.

\section{CONCLUSION:}

In this study, our in vitro studies revealed that resveratrol could activate the PGC- $1 \alpha$ and PPAR signaling and reduce cell proliferation in the two hepatoma cell lines by MTT assay. We also verified that the combined product can exhibit inhibition on mTOR signaling which represents an important mechanism in HBV tumorigenesis. Our results in the transgenic mice harboring double $\mathrm{HBx}$ and pre-S2 mutant construct showed that the combined silymarin and resveratrol product at a defined ratio of dosages may represent an ideal candidate agent for chemoprevention of HCCs because of their popular and long-term usage in human community. Silymarin and resveratrol have been reported to be effective at various stages of carcinogenesis including initiation, promotion, tumor invasion, and metastatsis [25-27, 29]. Clinical trial will be designed along this line to conduct on high risk chronic hepatitis B patients to prevent HCC development or to prevent the recurrence of their HCC after surgery.

\section{Competing Insterests:}

The authors have no financial interests or conflicts of interest.

\section{Authors' Contributions:}

Prof. Ih-Jen $\mathrm{Su}$ is the principal investigator for this study and wrote the manuscript. Wen-Chuan Hsieh contributed the study design and manuscript writing. Ching-Wen Yang organized the in vitro study and performed the MTT assay. Yi-Sheng Haung performed the 
PPAR activity assay and Western Blotting. Ting-Wei Chao took care of animal and Prof. Tin-Fen Tsai established the transgenic mice. Wen-Chuan Hsieh and Ching-Wen Yang contributed equally to these studies.

\section{Acknowledgements and Funding:}

The authors would like to thank National Health Research Institutes and Department of Health for the financial support.

\section{REFERENCES}

1. Jemal A, Bray F, Center MM, Ferlay J, Ward E, Forman D. Global cancer statistics. CA Cancer J Clin 2011;61:69-90.

2. El-Serag HB. Epidemiology of viral hepatitis and hepatocellular carcinoma. Gastroenterology 2012;142:1264-1273 e1261.

3. Gomaa AI, Khan SA, Toledano MB, Waked I, Taylor-Robinson SD. Hepatocellular carcinoma: epidemiology, risk factors and pathogenesis. World J Gastroenterol 2008; 14:4300-4308.

4. Liu LP, Liang HF, Chen XP, Zhang WG, Yang SL, Xu T, Ren L. The role of NF-kappaB in Hepatitis b virus X protein-mediated upregulation of VEGF and MMPs. Cancer Invest 2010;28:443-451.

5. Yen CJ, Lin YJ, Yen CS, Tsai HW, Tsai TF, Chang KY, Huang WC, et al. Hepatitis B virus $\mathrm{X}$ protein upregulates mTOR signaling through IKKbeta to increase cell proliferation and VEGF production in hepatocellular carcinoma. PLoS One 2012; 7:e41931.

6. Kew MC. Hepatitis B virus x protein in the pathogenesis of hepatitis B virus-induced hepatocellular carcinoma. J Gastroenterol Hepatol 2011;26 Suppl 1:144-152.

7. Su IJ, Wang HC, Wu HC, Huang WY. Ground glass hepatocytes contain pre-S mutants and represent preneoplastic lesions in chronic hepatitis B virus infection. J Gastroenterol Hepatol 2008;23:1169-1174.

8. Fan YF, Lu CC, Chen WC, Yao WJ, Wang HC, Chang TT, Lei HY, et al. Prevalence and significance of hepatitis B virus (HBV) pre-S mutants in serum and liver at different replicative stages of chronic HBV infection. Hepatology 2001;33:277-286.

9. Wang HC, Chang WT, Chang WW, Wu HC, Huang W, Lei HY, Lai MD, et al. Hepatitis B virus pre-S2 mutant upregulates cyclin A expression and induces nodular proliferation of hepatocytes. Hepatology 2005;41:761-770.

10. Wang HC, Huang W, Lai MD, Su IJ. Hepatitis B virus pre-S mutants, endoplasmic reticulum stress and hepatocarcinogenesis. Cancer Sci 2006;97:683-688.

11. Hsieh YH, Su IJ, Wang HC, Tsai JH, Huang YJ, Chang WW, Lai MD, et al. Hepatitis B virus pre-S2 mutant surface antigen induces degradation of cyclin-dependent kinase inhibitor p27Kip1 through c-Jun activation domain-binding protein 1. Mol Cancer Res 2007;5:1063-1072.

12. Yang JC, Teng CF, Wu HC, Tsai HW, Chuang HC, Tsai TF, Hsu YH, et al. Enhanced 
expression of vascular endothelial growth factor-A in ground glass hepatocytes and its implication in hepatitis B virus hepatocarcinogenesis. Hepatology 2009;49:1962-1971.

13. Teng CF, Wu HC, Tsai HW, Shiah HS, Huang W, Su IJ. Novel feedback inhibition of surface antigen synthesis by mammalian target of rapamycin (mTOR) signal and its implication for hepatitis B virus tumorigenesis and therapy. Hepatology 2011;54:1199-1207.

14. Reddy SK, Steel JL, Chen HW, DeMateo DJ, Cardinal J, Behari J, Humar A, et al. Outcomes of curative treatment for hepatocellular cancer in nonalcoholic steatohepatitis versus hepatitis $\mathrm{C}$ and alcoholic liver disease. Hepatology 2012;55:1809-1819.

15. Siegel AB, Zhu AX. Metabolic syndrome and hepatocellular carcinoma: two growing epidemics with a potential link. Cancer 2009;115:5651-5661.

16. Duan XY, Qiao L, Fan JG. Clinical features of nonalcoholic fatty liver disease-associated hepatocellular carcinoma. Hepatobiliary Pancreat Dis Int 2012;11:18-27.

17. Ertle J, Dechene A, Sowa JP, Penndorf V, Herzer K, Kaiser G, Schlaak JF, et al. Non-alcoholic fatty liver disease progresses to hepatocellular carcinoma in the absence of apparent cirrhosis. Int J Cancer 2011;128:2436-2443.

18. Powers T. Cell growth control: mTOR takes on fat. Mol Cell 2008;31:775-776.

19. Vinciguerra M, Veyrat-Durebex C, Moukil MA, Rubbia-Brandt L, Rohner-Jeanrenaud F, Foti M. PTEN down-regulation by unsaturated fatty acids triggers hepatic steatosis via an NF-kappaBp65/mTOR-dependent mechanism. Gastroenterology 2008;134:268-280.

20. Manning BD. Balancing Akt with S6K: implications for both metabolic diseases and tumorigenesis. J Cell Biol 2004;167:399-403.

21. Le Bacquer O, Petroulakis E, Paglialunga S, Poulin F, Richard D, Cianflone K, Sonenberg N. Elevated sensitivity to diet-induced obesity and insulin resistance in mice lacking 4E-BP1 and 4E-BP2. J Clin Invest 2007;117:387-396.

22. Duvel K, Yecies JL, Menon S, Raman P, Lipovsky AI, Souza AL, Triantafellow E, et al. Activation of a metabolic gene regulatory network downstream of mTOR complex 1. Mol Cell 2010;39:171-183.

23. Loguercio C, Andreone P, Brisc C, Brisc MC, Bugianesi E, Chiaramonte M, Cursaro C, et al. Silybin combined with phosphatidylcholine and vitamin $\mathrm{E}$ in patients with nonalcoholic fatty liver disease: a randomized controlled trial. Free Radic Biol Med 2012;52:1658-1665.

24. Polyak SJ, Morishima C, Lohmann V, Pal S, Lee DY, Liu Y, Graf TN, et al. Identification of hepatoprotective flavonolignans from silymarin. Proc Natl Acad Sci U S A 2010;107:5995-5999.

25. Hoh C, Boocock D, Marczylo T, Singh R, Berry DP, Dennison AR, Hemingway D, et al. Pilot study of oral silibinin, a putative chemopreventive agent, in colorectal cancer patients: silibinin levels in plasma, colorectum, and liver and their pharmacodynamic consequences. Clin Cancer Res 2006;12:2944-2950.

26. Wu YF, Fu SL, Kao CH, Yang CW, Lin CH, Hsu MT, Tsai TF. Chemopreventive effect 
of silymarin on liver pathology in $\mathrm{HBV} X$ protein transgenic mice. Cancer Res 2008;68:2033-2042.

27. Jang M, Cai L, Udeani GO, Slowing KV, Thomas CF, Beecher CW, Fong HH, et al. Cancer chemopreventive activity of resveratrol, a natural product derived from grapes. Science 1997;275:218-220.

28. Gusman J, Malonne H, Atassi G. A reappraisal of the potential chemopreventive and chemotherapeutic properties of resveratrol. Carcinogenesis 2001;22:1111-1117.

29. Fulda S. Resveratrol and derivatives for the prevention and treatment of cancer. Drug Discov Today 2010;15:757-765.

30. Zhu X, Liu Q, Wang M, Liang M, Yang X, Xu X, Zou H, et al. Activation of Sirt1 by resveratrol inhibits TNF-alpha induced inflammation in fibroblasts. PLoS One 2011;6:e27081.

31. Xia EQ, Deng GF, Guo YJ, Li HB. Biological activities of polyphenols from grapes. Int J Mol Sci 2010;11:622-646.

32. Guarente L. Sirtuins as potential targets for metabolic syndrome. Nature 2006;444:868-874.

33. Lekli I, Ray D, Das DK. Longevity nutrients resveratrol, wines and grapes. Genes Nutr 2010;5:55-60.

34. Lin HC, Chen YF, Hsu WH, Yang CW, Kao CH, Tsai TF. Resveratrol helps recovery from fatty liver and protects against hepatocellular carcinoma induced by hepatitis B virus X protein in a mouse model. Cancer Prev Res (Phila) 2012;5:952-962.. 